\title{
2006-1440: MATH AND SCIENCE ACROSS THE BOARD: CONNECTING PROFESSIONAL DEVELOPMENT TO CLASSROOM PRACTICES VIA AN EMBEDDED RESEARCH INITIATIVE
}

\section{Janet Lumpp, University of Kentucky}

Janet Lumpp is an Associate Professor in the Electrical and Computer Engineering Department at the University of Kentucky. She received her B.S.Met.E. and M.S.Met.E. degrees at Purdue University and a Ph.D. at The University of Iowa in Materials Engineering. As part of her NSF CAREER Award, she developed the concept of KEEP using microelectronics as a theme in math and science education and implemented the circuit project in middle school and high school classrooms. Dr. Lumpp teaches courses on electronic packaging, lasers, and circuit analysis. Her research areas include laser micromachining, electronic packaging, sensors and K-16 STEM education.

\section{Kelly Bradley, University of Kentucky}

Kelly D. Bradley is an assistant professor in the Department of Educational Policy Studies \& Evaluation at the University of Kentucky. She teaches research methods and statistics. Her expertise is survey research and Rasch measurement. Teacher supply and demand issues, especially in math and science, are at the forefront of her research agenda. Dr. Bradley holds a M.S. in statistics from the University of South Carolina, a B.S. in mathematics and sociology and a B.A. in mathematics education from Fairmont State College and a Ph.D. in Quantitative Research, Evaluation and Measurement in Education from The Ohio State University. 


\title{
Math and Science across the Board: Connecting Professional Development to Classroom Practices via an Embedded Research Initiative
}

\begin{abstract}
With rising expectations of the educational community, general public and state/national policy makers, it is imperative that new curricula and teacher training programs adhere to the rigor and high standards presented in No Child Left Behind. Over the past eight years, the Kentucky Electronics Education Project (KEEP) has grown from an outreach project into an embedded research initiative. KEEP utilizes a microelectronics theme to connect math and science standards based lessons with hands-on real world applications. Efforts to date include teacher training, hands-on circuit building activities, construction/validation of training and classroom evaluations and standards-based lessons. This paper demonstrates the alignment of KEEP concepts with national math, science and technology standards, overviews the circuit project steps, reports empirical findings and summarizes current progress toward long term objectives.
\end{abstract}

\section{Introduction}

The concept of Kentucky Electronics Education Project (KEEP) started as the educational component of a National Science Foundation Career Award with the goal of using the multidisciplinary microelectronics theme to connect real world content with K-12 classroom education. Over the past eight years, KEEP has grown to include professional development workshops, interdisciplinary collaborations across the university and industry, classroom implementations and research, resulting in an effective educational intervention. The long term goals of KEEP are to (1) to develop a sustainable professional development model that supports the transition from training to classroom implementation; (2) to create a learning community of high quality STEM teachers, informed administrators, interdisciplinary university faculty and industry partners; (3) to enhance the quality of teacher instruction and support gains in student achievement; (4) to construct reliable and valid assessment tools for student and teacher content knowledge and (5) to increase student interest in STEM curricula and careers. Summarized below is the progress that has been made on each of these fronts, discussion of challenges along the way and the continuing plans to successfully accomplish the missions of KEEP.

The training and development phases are comprised of three main components: professional development workshops for teachers, development of math and science lessons and units and production of a CD-ROM resource. The CD-ROM is a collaborative effort of the research team, industry partners and public television to produce a resource for teachers and students that provides a tutorial via video segments on each project step, an illustration of applications through a virtual plant tour and background information. The CD-ROM will serve as a companion to teachers implementing the lessons in their classrooms, reducing the anxiety associated with introducing new concepts and materials into the classroom setting. In addition, teachers that implement components of the project have the support of the research team. Using the resources and training received through professional development workshops, teachers implement KEEP activities in their classrooms, embedding it within their curriculum - in contrast to extending the already growing demands of content coverage. 
Data-based decision making is the expectation within classrooms and this extends to KEEP. The training, development and implementation are all being studied. During the past three years, KEEP has matured into a collaborative research program of the University of Kentucky Colleges of Engineering and Education with the main objective being to improve grade 5-12 science, technology, engineering and mathematics (STEM) education through circuit building activities that expand beyond the traditional "bulbs and batteries" approach to teaching and learning about electricity. Considering the breadth and depth of microelectronics, there is no shortage of examples and technology applications connected to educational standards, such as copper etching, semiconductors, insulators, conductors, energy conversion, and heat transfer which readily link to national standards on math, physical science, science and technology, environmental issues and science as inquiry.

Philosophical and empirical data collection is used to document the impact of the initiative and evaluate ways to improve the KEEP process of training and implementation. Students and teachers participating in the sessions complete baseline and post-activity evaluations via penciland-paper surveys comprised of questions on demographics, classroom environment, aspects of the project and open-ended responses. Measurement and statistical models are employed to analyze quantitative data. Subsequent measurement analyses (which utilize Rasch measurement models) are examined using statistical techniques. Open-ended items are analyzed using a content analysis with a thematic approach. Multiple years of survey results from high school science and pre-engineering students indicate a high general level of satisfaction with the project. Students identify their least favorite parts of the project as those they view to be the most challenging. Limitations of the KEEP activities are also identified by students and teachers, including the variation in math and science classroom settings from full labs to the limited accessibility of electrical outlets. Early success indicators include students consistently reporting their interest in taking more classes that incorporate this type of activity, teachers attending additional training sessions and introducing their colleagues to the curriculum, endorsement of principals and superintendents to financially support the activity and the growing interdisciplinary collaborations within and beyond the university.

\section{Literature Review}

Over the past decade, there has been a call for an expansion and revision of the traditional professional development model in an attempt to improve effectiveness and accountability. 1,2,3,4,5 In his presentation at the 2003 American Educational Research Association annual meeting, Guskey provided a synthesis of twelve research-based points of effective professional development. $^{5}$ This synthesis indicated that learning of content and pedagogical knowledge was the most frequently cited PD criteria. The second was time spent, with the consideration that the time was well-structured and aimed specifically at content and pedagogical knowledge. ${ }^{3}$ Garet et al agree that "... sustained and intensive professional development.... [with a focus on] academic subject matter... is more likely to produce enhanced knowledge and skills." ${ }^{2}$ In the three-year analysis of math and science teachers' professional development experiences, the importance of hands-on activities and their integration into the school context were documented. 
Another consistent theme in Guskey's synthesis is the need for peer collaboration and a focus on encouraging teacher community, a finding that has now emerged as a repeating theme within the literature $^{1,6,7}$ This focus is included in the National Staff Development Council's (NSDC) Standards for Professional Development. ${ }^{8}$ In his synthesis, Guskey did not find evidence of "Data-Driven" or "Family Involvement" NSDC Standards, but in the context of No Child Left Behind, these characteristics must surface and will become increasingly important. ${ }^{9}$

Increasing the expectations for professional development requires an evaluation process that reflects the critical characteristics of effective PD. Kirkpatrick's 4-levels, with over 40 years of use in evaluation and formative assessment, outline this process: "Reaction" (perception of the PD experience), "Learning" (gains in content knowledge), "Behavior" (the extent to which the training is transferred to classroom practice) and "Impact" (best viewed in today's context by gains in student achievement). ${ }^{10,11,12}$ There are limited examples of the direct application of evaluations like Kirkpatrick's levels to PD evaluation. In particular, the tie between professional development and student achievement has been difficult to establish. ${ }^{12}$ As Guskey noted in his presentation, "... research rarely includes rigorous investigations of the relationship between the noted characteristics and improvements in instructional practice or student learning outcomes," the last two of Kirkpatrick's levels. ${ }^{5}$ Nevertheless, in this age of heavy commitment to student assessment, and teacher and program accountability, the Kirkpatrick evaluation model provides a rigorous way to address the complex demands of today's professional development models.

Successful teacher education initiatives create a set of experiences that encourage participating teachers to become genuine "learners" in situations intended to model a proposed instructional approach. ${ }^{13,14}$ Like students, teachers must be actively involved in learning, with opportunities to discuss, reflect upon, and try out instructional approaches. Positive, self-sustaining curricular changes are most likely to occur when teacher learning takes place within a professional community that is nurtured and developed from with the school and beyond. Teachers need PD that extends far beyond the one-time workshop; they need opportunities to learn how to question, analyze, and change instruction to teach challenging content. ${ }^{15}$ Simon's "Learning Cycles" model suggests that teachers learn through "involvement in situations that engage them actively; raising cognitive dissonance and, thus, initiating new constructions of meaning; sharing and discussing these constructions with a group so as to come to some consensus and generalizations; and, applying these generalizations to new situations, thus starting the learning cycle all over

again at a higher level". ${ }^{16}$ Support for actively engaging teachers in PD also derives from research on the learning of complex tasks. The model proposed by Collins and his colleagues, ${ }^{17}$ identifies three key phases in this process: "modeling", where the learner can observe and examine how an expert engages in the task; "scaffolded practice", where the learner engages in the task him/herself, but with the help of the instructor and/or of other supporting structures; and "independent practice", where ultimately the learner engages in the task without support.

\section{Multiphase Model}

The collaborative efforts of KEEP seek to improve STEM teacher quality and strengthen the STEM profession by building a web of interconnected teachers and supporting the expansion of the web across the professional continuum. The method combines multiphase microelectronics 
PD with a STEM PD Research web (SPDRweb). Figure 1 (see below) illustrates the model, which uses a spider web as the visual framework.

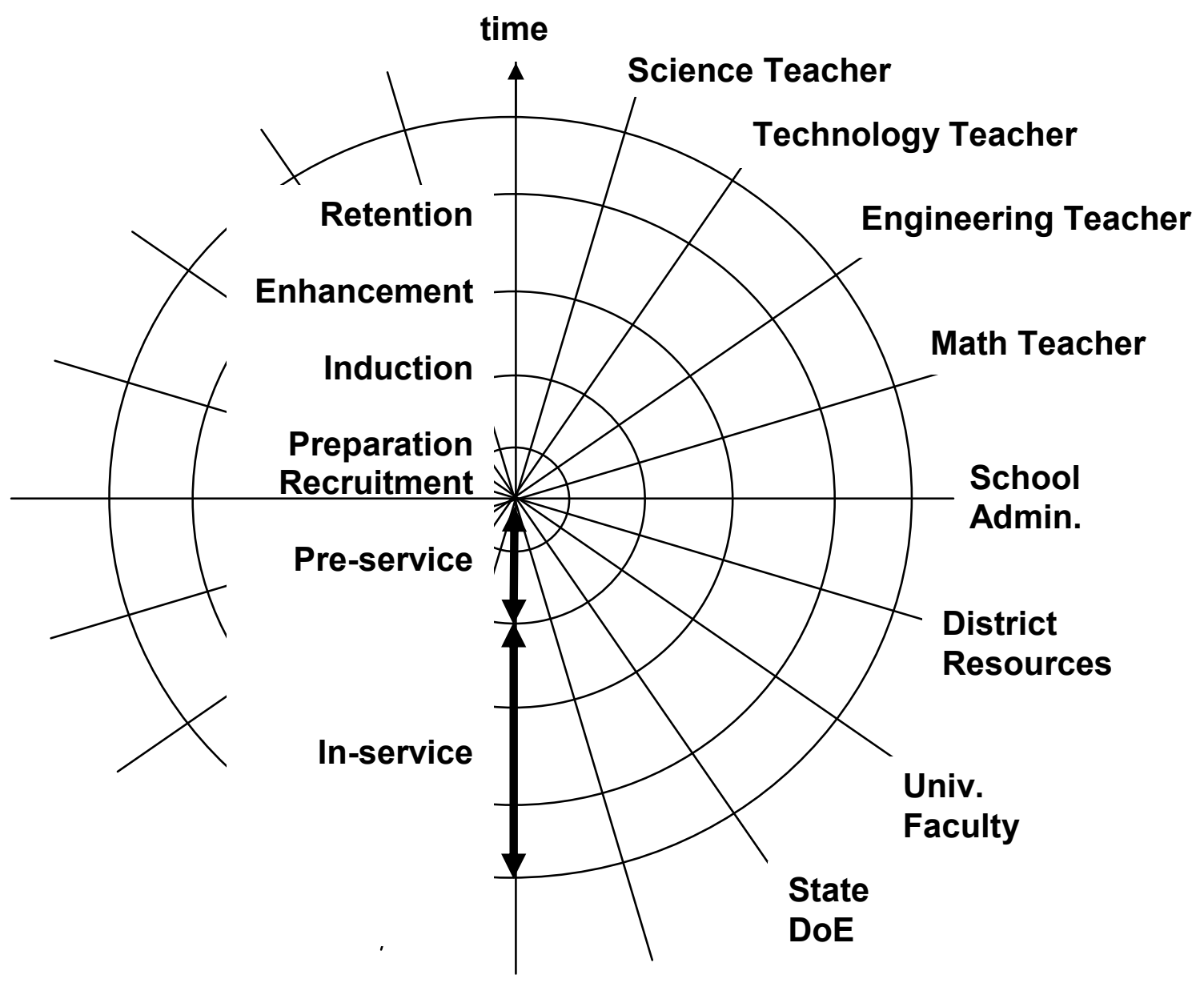

Figure 1. STEM PD Research Web (SPDRweb) model.

The concentric rings of the web represent the critical transition points in a teaching career, with recruitment at the center and each larger ring corresponding to preparation, induction, enhancement and retention, respectively, as time increases from the center outward. The spacing between the rings indicates time spent in pre-service education and as an in-service professional. Each radial strand of the web represents an individual or organizational unit, including teachers from each of the STEM disciplines, curriculum coordinators, school administrators, district resource offices, state departments of education, and university faculty.

The model addresses the challenges set out in the literature through on-going professional development, promoting partnerships and providing cross-disciplinary content knowledge. Through repeated training opportunities, teachers receive sustained and intensive PD with emphasis on hands-on activities, connections to core content and a cross-disciplinary approach 
connected to STEM academic subjects. Training pre- and in-service teachers side by side reinforces the expectation that teachers become learners in order to become better teachers. To encourage teacher community development, KEEP PD emphasizes partnerships of teachers at various stages of the professional continuum and team teaching across disciplines. Attempting to build a STEM web through PD by bringing together groups of teachers and presenting STEM content from the individual disciplines will not automatically generate partnerships or prevent attrition. Our model interconnects STEM teachers across disciplines and across the professional continuum using a cross-disciplinary theme to anchor the strands of the web. The field of microelectronics is inherently cross-disciplinary looking both inward at the fundamentals and outward at the real world applications. ${ }^{18}$ To complete the SPDRweb, it is imperative that the effectiveness of the model be evaluated and the results be reinserted into the design. Doing so, actively involves teachers and students so they are no longer subjects of research, instead they active participants, core to the collaborative efforts.

\section{Microelectronics Theme for STEM PD and Instruction}

Electronic devices are abundant in our society, making it an accessible theme which connects math and science core concepts. Circuit boards are comprised of various materials, designed using mathematical and symbolic tools, assembled by high precision automated manufacturing methods and impact our environment, economy, and quality of life. Instructional units based on the microelectronics theme explore these connections. For example, teachers and students may explore the path of discarded obsolete personal computers - are they sent to landfills or to a recycling center - considering the advantages/disadvantages of each destination. Numerous additional lessons can draw from the breadth of microelectronics to present, connect, explore and test STEM principles. Within a classroom setting, students parallel the industrial process and build complete working circuits starting from basic materials, components and hand tools.

The following illustrations of 'standards benchmarks' illustrate how KEEP initiatives directly address the state Core Content in Science in grades 5-12. Students entering fifth grade are expected to know that "Electricity in circuits can produce light, heat, sound, and magnetic effects. Electrical circuits require a complete conducting path through which an electrical current can pass ( $4^{\text {th }}$ grade assessment SC-M-1.3.3)." Electrical continuity is explored through a multimeter scavenger hunt testing objects in the classroom to find conductive and nonconductive materials. One of the KEEP circuit projects built over the past four years is a continuity tester, which serves the same purpose as the short circuit/open circuit beeping mode of the multimeter. Continuity is further explored by soldering to complete the electrical path between the copper conductor line on the circuit board and the component lead sticking through the board.

Students in grades 5-7 are expected to be able to understand and apply the following transfer of energy concept as part of the Physical Science sequence of instruction "Electrical circuits provide a means of transferring electrical energy when heat, light, sound, and chemical changes are produced. (SC-M-1.3.5)." Standards SC-H-1.2.1 and SC-H-1.2.3 state that Grade 8-12 students must understand "Bonds between atoms are created when outer electrons are paired by being transferred or shared. A compound is formed when two or more kinds of atoms bind together chemically" and "In conducting materials, electrons flow easily; whereas, in insulating 
materials, they can hardly flow at all. Semiconducting materials have intermediate behavior. At low temperatures, some materials become superconductors and offer no resistance to the flow of electrons." The KEEP circuit projects, as in most consumer electronics, utilize circuit boards composed of glass fibers, epoxy, and copper representing glass, polymer and metal materials, and electronic components composed of glass, polymer, metal, ceramic and semiconductor materials. By using all types of materials, circuits can take advantage of the properties of materials needed to control the function of the circuit and to bond the components together.

Middle and High School Core Content for Mathematics (and NCTM) standards MA-M-3.2.13.2.7 and H-M-3.2.1-3.2.6 state that students must be skilled in performing mathematical operations and/or procedures accurately and efficiently, and be able to explain how they work in real-world and mathematical situations. The list of such skills includes being able to: organize, represent, analyze, and interpret sets of data; construct and interpret displays of data (e.g., table, circle graph, line plot, stem-and-leaf plot, box-and-whiskers plot), mean, median, mode, and range; recognize outliers, gaps, and clusters of data; calculate theoretical probabilities and tabulate experimental results from simulations; make predictions and draw conclusions from statistical data and probability experiments; use counting techniques, tree diagrams, area models, and tables to solve probability problems; represent probabilities in multiple ways such as fractions, decimals, percents, and area models. KEEP instructional units address these math standards through activities on drawing a circuit board layout according to its electrical schematic and parts list, unit conversions between English and metric systems, binary numbers and Boolean algebra as related to logic circuits and statistics using the electronic dice circuit.

The National Science Education Standards (NSES) student standard "A1: Science as Inquiry" and "E1: Science and Technology" reiterate the importance of empirical design. An example of the design and conducting of experiments in KEEP are the failure analysis studies such as drop tests, vibration tests, or thermal shock cycles. Students can design the parameters of the studies, count the cycles to failure and analyze how the circuit failed as an interdisciplinary STEM project. Student portfolios include the process of their work by outlining their hypotheses and test methods, providing failure criteria, reporting results, recognizing related STEM standards and providing written responses about the project's connections to the real world.

\section{Circuit Fabrication Process}

Since 1998, over 800 students and 90 teachers have participated in KEEP classroom implementations and workshops, to date. The full circuit-building sequence is described below (see Table 1) and requires at least three hours to complete. A minimized sequence allows participants to bypass the patterning steps and move ahead to the drilling and soldering phases, greatly reducing the time while retaining the opportunity for learning. Circuits are assembled using a hobbyist approach ${ }^{19}$ employing hand tools to parallel the steps used in industry. Teachers attending two- or three-day PD workshops are provided a Circuit Assembly Toolkit containing hand tools and supplies including: a soldering iron, solder, solder wick, pliers, wire strippers, wire cutters, scouring pad, permanent marker, drill, drillbits, wooden board, and iron. Individual circuit project kits include: circuit board, iron-on pattern, battery, and electronic components. 
Table 1. Circuit Building Process Sequence

1. Prepare the pattern on the iron on transfer paper.

2. Trim the pattern to the size of the board.

3. Clean the copper surface thoroughly with a scouring pad.

4. Wash the board in water and dry.

5. Preheat the iron to the beginning of the steam setting without steam.

6. Prepare a tray of water.

7. Place the circuit board on the wooden board with copper facing up.

8. Place the pattern face down on the copper.

9. Press firmly with the hot iron for 5 minutes moving every 1 minute. DO NOT slide the iron.

10. Place the circuit board in the tray of water with the paper facing up.

11. Wait for the paper to float off the board.

12. Dry the board.

13. Inspect the pattern and repair any missing lines with the permanent marker.

14. Label the circuit board with your initials if you are processing multiple boards.

15. Mix the etchant powder in water at the proper ratio.

16. Preheat the etchant solution to $40-70^{\circ} \mathrm{C}$.

17. Place the patterned circuit boards into the etchant bath.

18. Stir occasionally and monitor the temperature.

19. Remove the etched boards, rinse with clean water, and dry.

20. Drill holes.

21. Scrub off remaining toner with scouring pad or rinse with acetone.

22. Preheat soldering iron.

23. Wet soldering iron sponge.

24. Insert components, clinch, solder, and trim leads.

25. Test circuit.

26. Troubleshoot and repair as needed.

Cleaning the copper surface is a critical step in the process. If this step is not conducted properly, the toner will not adhere to the copper. The toner is printed on the transfer paper using a laser printer or photocopier and is heat bonded to the copper using a clothing iron. In the etching bath, the toner and permanent marker serve as the etch resist protecting the copper lines of the circuit pattern. Figure 2 presents the electrical schematic and layout pattern for the flashing LED project. 

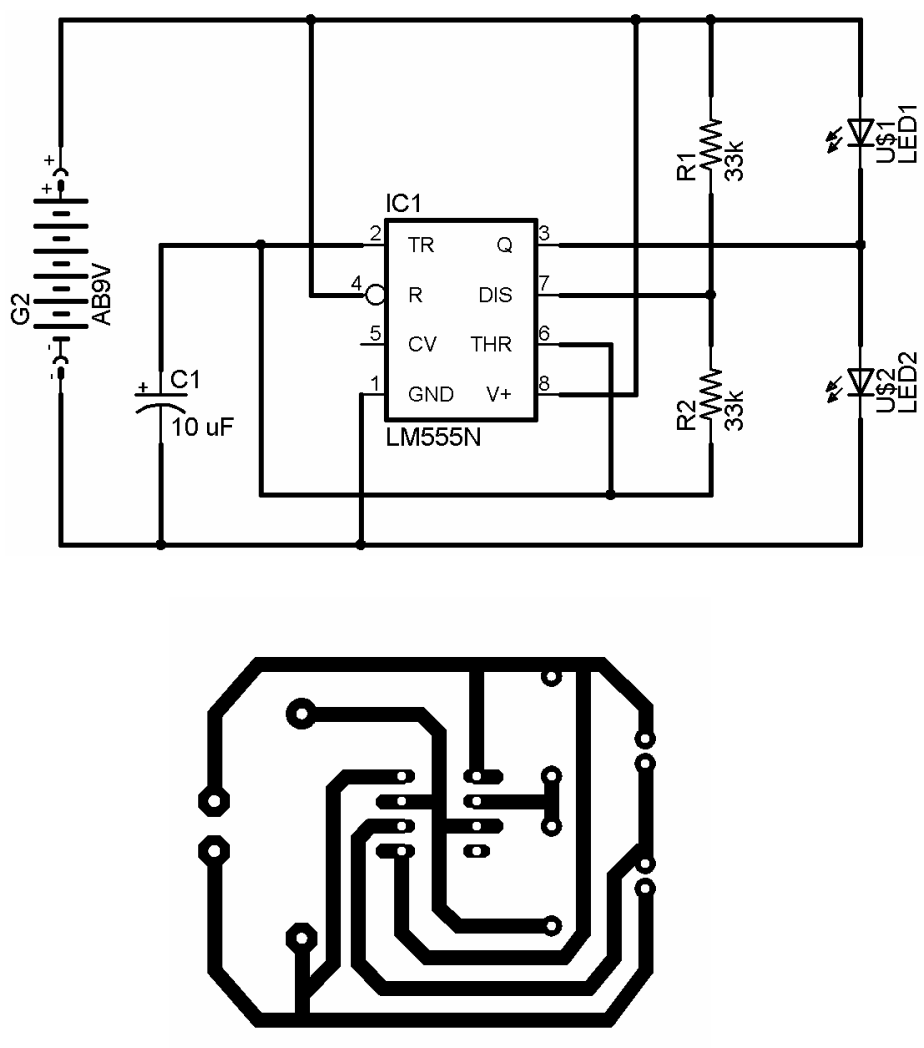

Figure 2. Electrical schematic and layout pattern for flashing LED circuit project.

The etching bath is a commercially available etchant acid prepared by dissolving sodium persulfate salt in water. The reaction rate increases with temperature and decreases with the number of boards being etched. Safety precautions such as goggles and gloves are required when working with the etchant materials. Goggles are also recommended during the drilling stage. All of the components used in KEEP projects are through hole type devices with wire leads and pins, so hand drills and power rotary tools are used to drill through the circuit board, creating a hole for the component leads to be inserted. Components are inserted from the blank side of the board with the leads protruding through the copper pattern for soldering. During the circuit-building process, participants learn to identify basic components, determine proper orientation, and place the components according to the diagrams provided on the handouts.

\section{Professional Development Workshop Format}

KEEP PD workshops range from half day introductions to complete two- or three-day programs. The schedule rotates between presentations, group discussions and hands-on activities. Participants also complete baseline and post-training surveys. Lecture topics cover review of relevant STEM content knowledge, standards related to the microelectronics theme, and implementation strategies. Hands-on activities include learning to solder and desolder, drawing a circuit board layout from a schematic, reading the resistor color code, and using a multimeter. Each workshop begins with instruction on how to solder and desolder on practice circuit boards. 
Next, the participants drill holes in circuit boards that have already been etched with the copper pattern for a flashing LED (light emitting diode) circuit. The components for the LED circuit are then reviewed and inserted into the correct locations on the board ready to be soldered. Extended workshops proceed to follow the complete process sequence to build a variable buzzer circuit having participants scrub a bare circuit board to remove oxide residue, iron-on and repair the pattern, etch the excess copper, and then repeat the drill, insert, and solder steps learned previously. The cycle of learning the last steps first, has effectively trained people to solder and repair their projects while helping to minimize their anxiety with unfamiliar techniques. Each step is modeled by the workshop leader and individual coaching is offered. The process sequence is forgiving and allows repairs to be made at each stage. The flexibility to repair mistakes reduces the pressure to perform perfectly on a task that is being attempted for the first time and illustrates to the participating teachers the flexibility of the project when implementing it within their own class settings.

Teachers and students who complete a workshop or circuit building project have a tremendous sense of pride in having accomplished a unique activity and having a final product [the working circuit] that they may show their friends, families and colleagues. Feedback comments on the workshops indicate that the format and content were unlike typical professional development courses and that they enjoyed the hands-on emphasis over traditional oral presentations. ${ }^{20}$ Despite the enthusiasm generated during the workshops, limiting issues have surfaced when it comes to teacher's implementation of KEEP activities in their classrooms. ${ }^{21,22}$ The leading issue is likely teacher confidence, as teachers need to be able to setup and supervise the circuit building steps based on their limited experience in the training session. A related issue is teacher isolation within their discipline in their school. For example, a math teacher who has taken the workshop may need access to a science classroom with sinks and extra electrical outlets. Having enough kits to supply a classroom is a practical limitation, because if only one teacher from a school attends the workshop, they will need to purchase several more kits in order to implement the activity in their school. Finally, the circuit building activity takes several class periods to complete, and the teachers need to be able to justify the expenditure of time and resources on a new program. To minimize many of these concerns, a CD-ROM resource has been produced for distribution to teachers who have completed workshops. The CD contains video segments of the instructor performing and explaining each of the process steps. A plant tour of a local circuit board contract manufacturer is also included on the disk, along with all of the handouts, instructions, and vendors. Teachers can review the process steps before leading their students through the activity or show the steps to the class as part of the instructional unit.

\section{Results from Implementations}

\section{Half Day Programs}

The buzzer and flashing LED projects have been drilled and soldered by students in half day programs with two to three hours allotted for the project. Students first learn to solder and desolder, then proceed to drill and assemble their circuits. An introductory lecture is given on circuit board materials and types of components with commercial circuit boards as examples. If time allows, teams of students are given multimeters and allowed to explore the room to find conductive and non-conductive materials. The multimeters have a short circuit test mode where 
they emit an audible beep when the two probes are in contact with a conductive material. As a group, the students compile a list of conductive and non-conductive items and summarize the types of materials in each category. KEEP instructors have taught half day projects for high school students in Appalachia (Rogers Scholars), middle school girls (Girls in Science), and high school girls (Young Women in Science).

In conjunction with the Girls in Science middle school groups, teachers from the same schools were invited for a three day professional development workshop including a one half day introduction to KEEP. The session included an overview of the theme, learning to solder and desolder, and building the flashing LED circuit. Surveys constructed for the girls and teachers included questions regarding the learning environment in their classrooms covering issues such as the use of technology, group activities, arrangement of desks in the classroom, and hands-on projects. The results of 57 girls and 20 teachers surveyed explored the important aspects of the learning environment and correlations between specific aspects. For example, student surveys indicate that being encouraged to ask questions in class correlates with the perception that the assignments are meaningful, and the use of technology correlates with enjoyment of the atmosphere in the classroom. Even higher correlations were found in the teacher survey results on issues such as the impact of teaching style on student learning associated with students viewing their classroom environment positively, and the arrangement of desks to allow students to collaborate associated with regular implementation of group work.

\section{Classroom Implementations}

Initially, in part to get KEEP activities 'up and running' in the classroom setting, KEEP instructors supplied the necessary resources to a school and lead the circuit building activity over several days. In more recent implementations, teachers who have attended KEEP workshops are taking an independent implementation approach. A fifth grade science teacher uses commercially prepared kits to teach her classes about components, circuits and soldering. At the end of the unit, students are given a performance assessment that requires them to drill, assemble and solder a KEEP project. High school science teachers incorporate the full circuit project into sophomore chemistry/physics courses and a pre-engineering elective course for juniors and seniors, with the sophomores building a continuity tester and the upperclassmen building the most complicated KEEP project, an electronic dice circuit.

With each implementation, the KEEP research team requests that evaluations of the project are completed by participating students and corresponding teachers. The analysis of the responses of high school students and teachers over a two-year period is presented in another publication ${ }^{23}$ and summarized here. The evaluations utilize a five-point Likert-type scale, where teachers and students rated their agreement with various statements. In addition, participants are provided an opportunity to expand on their ratings and provide further insights via open-ended questions. Analysis demonstrates reliable and valid teacher and student perception instrumentation. Data collected from 202 high school students that completed an evaluation following the KEEP implementation were analyzed using the Rasch model via WINSTEPS software. The mean measure, expected to be 0 , is 1.42 , implying that it is easy for students to assign high scores to the items, indicating high satisfaction with the project. Students describe their experience with the project as a fun learning experience with soldering as their favorite process step. In general, 
they identified the most personally challenging step as their least favorite, but indicate a willingness to complete another circuit project in the future. The open responses reveal that the project reinforces the science content they have learned about electricity, complete circuits, and electrical energy.

\section{Discussion of Current Status}

The shortage of well-qualified STEM teachers and concomitant shortage of well prepared students entering post-secondary institutions are the motivation for the SPDRweb model and KEEP approach to refilling the pipeline. Several key strands of the web have been established and efforts continue to develop partnerships that will enhance and expand the network. To date, the hands-on project methods have been thoroughly tested and are now a robust, reproducible, flexible, tolerant process suitable for students in grades 5-12. KEEP offers four circuit projects with increasing complexity, using a variety of electronic components. The supporting handouts and resource materials are available along with several instructional units. As a starting point to include other grade levels and develop additional less plans, the microelectronics theme has been mapped onto the math and science standards. The CD-ROM resource has been distributed for review to teachers who are implementing the projects or have attended a KEEP workshop. The current SPDRweb strands include the College of Engineering, College of Education, public television station (KET), local industry (SMC, Inc.), naval research laboratory (Crane NSWC), local school district (Fayette County Public Schools), and Appalachian school districts in Eastern Kentucky, and are connected by in-service teachers at various career stages. The connection of teachers across disciplines at different career stages has had initial success as recent KEEP PD workshops trained several teachers from the same school representing math and science departments. Following Simon's cycles of learning, our PD format emphasizes the "modeling" phase where each step is demonstrated and repeated. The "scaffolded practice" phase has been used to help teachers overcome the confidence barrier and begin "independent practice" by assisting teachers in their classrooms. The CD-ROM resource will expand the influence of scaffolded practice by improving confidence and reducing isolation, thereby moving more teachers to independent practice regardless of their geographic location.

In the long term, it is expected that training will extend to the teacher training departments in the College of Education to train pre-service teachers and their cooperating teachers together in preparation for their student teaching period, an example of modeling. Implementation carried out during the student teaching period would be supported as scaffolded practice. The SPDRweb would naturally expand as the pre-service teachers are placed in permanent teaching positions. Trained teachers would be encouraged to form cross-disciplinary teams within their schools. The KEEP team would follow-up with the same teachers offering a second round of training with their new partners to increase their skills and content knowledge, to improve their confidence with the process steps and to assist in integrating KEEP into their curriculum. Even the highest quality PD experiences and materials will not impact student performance if the teachers do not transfer the PD into classroom practice. A significant outcome, therefore, of the KEEP multiphase PD model is the actual teacher implementations, during the student-teaching period and thereafter. 


\section{Conclusion}

The scope of KEEP and the impact of the SPDRweb have no boundaries. Beginning as a PD activity, it develops into a STEM community filled with current classroom teachers, mathematicians and scientists, university faculty, students at all grade levels and community and industry partnerships. Upon participating in the PD activities, pre-service and classroom teachers receive benefits of the cross-disciplinary program. When these teachers return to their schools and utilize components of KEEP, the school community benefits from the well qualified teachers and cross-disciplinary instructional materials. Students are offered a new hands-on approach to STEM, other faculty are encouraged to engage in such learning activities, and administrators see the benefits of PD in creating an engaging learning environment. The SPDRweb model assists other researchers in math, science and education by providing a model for team teaching at the University level and in creating a true K-16 learning environment, where students, teachers, and communities for school-aged, undergraduate and graduate studies are involved in curriculum improvement as a team. KEEP has the ability to impact any individual or program working to improve STEM curriculum development and learning success.

\section{Acknowledgements}

The work presented here was supported by the University of Kentucky College of Education, College of Engineering Alumni Donations, and the Office of the Executive Vice President for Research.

\section{Bibliography}

${ }^{1}$ Clark, R. (1998). Learning vs. Performance: Retention and Transfer of Knowledge and Skills from Long-Term Memory. In Building Expertise, Cognitive Methods for Training and Performance Improvement (pp. 83-94). Washington, DC: International Society for Performance Improvement.

${ }^{2}$ Garet, M. S., Porter, A. C., Desimone, L., Birman, B. F., \& Yoon, K. S. (2001, Winter). What makes professional development effective? Results from a national sample of teachers. American Educational Research Journal 38(4), 915-945.

${ }^{3}$ Guskey, T. R. (1999). New perspectives on evaluating professional development. Paper presented at the annual meeting of the American Educational Research Association. Montreal, 19-23 April.

${ }^{4}$ Guskey, T. (March, 2002). Does it make a difference? Evaluating professional development. Education Leadership, Association for Supervision and Curriculum Development (ASCD), p. 46-51.

${ }^{5}$ Guskey, T. R. (2003). What makes professional development effective? Phi Delta Kappan, 84 (10), $748-750$.

${ }^{6}$ Miles, K. H., \& Darling-Hammond, L. (1998). Rethinking the allocation of teaching resources: Some lessons from high-performing schools. Educational Evaluation and Policy Analysis, 20(1), 9-29.

${ }^{7}$ Supovitz, J.A. (2002). Developing communities of instructional practice. Teachers College Record 104 (8), $1591-$ 1626.

${ }^{8}$ National State Development Council. NSDC Standards for Staff Development, 2003 Retreived on May 25, 2005 at http://www.nsdc.org/standards/index.cfm

${ }^{9}$ Darling-Hammond, L.,\& Youngs, P. (2002). Defining "Highly Qualified Teachers": What Does "ScientificallyBased Research" Actually Tell Us? Educational Researcher, 13-25.

${ }^{10}$ Winfrey, E.C. (1999). Kirkpatrick's Four Levels of Evaluation. In B. Hoffman (Ed.), Encyclopedia of Educational Technology. Retrieved January 18, 2006, from http://coe.sdsu.edu/eet/Articles/k4levels/start.htm

${ }^{11}$ Watkins, R., Leigh, D., Foshay, R., \& Kaufman, R. (1998) Kirkpatrick Plus: Evaluation and Continuous Improvement with a Community Focus. Educational Technology Research and Development, 46(4), 90-96. 8

12 Orlich, D.C. (1989). "Staff development: Enhancing human potential." Boston: Allyn and Bacon.

${ }^{13}$ Friel, S.N., \& Bright, G.W. (Eds.). (1997). Reflecting on our work: NSF teacher enhancement in K-6 mathematics. Lanham, MD: University Press of America. 
${ }^{14}$ Schifter, D. and Fosnot, C. (1993). Reconstructing Mathematics Education. NY: Teachers College Press.

${ }^{15}$ Darling- Hammond, L. and McLaughlin, M.W. (1995) 'Policies that support professional development in an era of reform' in Phi Delta Kappan, April 1995 (Online: www.middleweb.com/PDPolicy.html accessed on 6/11/00).

${ }^{16}$ Simon, M. (1994). Learning mathematics and learning to teach: Learning cycles in mathematics teacher education. Educational Studies in Mathematics, 26.

${ }^{17}$ Collins, A., Brown, J. S., \& Newman, S. E. (1989). Cognitive apprenticeship: Teaching the crafts of reading, writing, and mathematics. In L. B. Resnick (Ed.), Knowing, learning, and instruction: Essays in honor of Robert Glaser (pp. 453-494). Hillsdale, NJ: Lawrence Erlbaum Associates.

${ }^{18}$ Tummala, R.R., Fundamentals of Microsystems Packaging, McGraw-Hill, New York, NY, 2001.

${ }^{19}$ Ball, L., "Make your own PC boards using toner-transfer products", Electronics Now, 68, 48-51. (1997).

${ }^{20}$ Lumpp, J.K., "KEEP - Kentucky Electronics Education Project: Microelectronics as a Theme in Math and Science", National Educators Workshop NEW: Update 2002, NASA/CP-2003-212403, pg 319-331, San Jose, CA, October 2002.

${ }^{21}$ Bradley, K.D., Lumpp, J.K., Toth, G. and Toy, B. "What Matters Most is Research in the Schools", Symposium, Mid-Western Educational Research Association, Columbus, OH, October 2003.

${ }^{22}$ Lumpp, J.K., and Bradley, K.D., "Development and Dissemination of KEEP - Kentucky Electronics Education Project", Proceedings of the Elec. Comp. \& Tech. Conf., New Orleans, LA, May 2003.

${ }^{23}$ Lumpp, J.K., Bradley, K.D., and Haines, R.T., "Kentucky Electronics Education Project (KEEP): Putting Professional Development into Practice", International Journal of Engineering Education, accepted for publication, January 2006. 